\title{
PROPERTY TAXATION AS THE BASIS OF LOCAL BUDGET IN THE RUSSIAN FEDERATION ${ }^{1}$
}

\author{
Petr V. Pereverzev \\ Volgograd State University, Volgograd, Russian Federation
}

\begin{abstract}
Introduction: the equitable distribution of financial resources is one of the main problems of a law-governed state. On a nationwide scale making decisions on forming the system of profitable sources of the local budgets and distributing the funds of the state budget is intended to ensure the implementation of the state functions in the conditions of a limited income. In the legal regulation of these activities a key role is played by the interpenetration of the norms of tax, budgetary and municipal law. In the modern legal science there have not been developed any clear ideas of the concept of "property" for the tax purposes. The special aspects of the modern legal regulation of this scientific problem deserve the researchers' attention. The purpose of the research is the need to formulate new approaches to the redistribution of the budget revenues of the Russian Federation, with the transfer of authority of collecting main receipts and spending them to the municipal entities. Today in the Russian legal science there are no fundamental developments based on the systematization, interpenetration and unity of the norms of different branches, such as budget, tax and municipal law. The methodological framework for the research is the general scientific methods of cognition. In particular, the formal legal method involves the study of the legal basis of the current budget and tax legislation regulating the issues of forming profitable sources of the local budgets; the system analysis of the object reveals the essential characteristics of property as an object of local taxation; the comparative historical research method allows to highlight the peculiarities of the legal regulation of the local taxation (in terms of revenue sources and spending areas of the budget) at different stages of the historical development; the comparative law method allows to identify the different approaches to property taxation in different countries. Results: the author specifies the definition of the essential features of the concept of "property" for the tax purposes, as well as identifies a range of problems arising in the application of the new regulatory framework, which aims to provide reforming the system of property taxation in the Russian Federation. Conclusions: in the scientific article the stages of forming and developing the local property taxation, as well as the problems of its reforming are highlighted. The author offers the ways of solving the problems that have arisen in connection with the ongoing reform of the local property taxation in modern Russia. The scope of the research results: the scientific article is of theoretical and applied nature. The selected scientific approaches allow solving both a range of theoretical problems of the complex of financial and municipal law branches and contribute to understanding the budget and legal activities of a federal state. The applied nature of the research may be used for improving the financial and legal mechanism of ensuring the constitutionally reasonable and effective formation of the revenue sources system of local taxation.
\end{abstract}

Key words: property tax, tax system, local taxation, land tax, cadastral value, local budget.

УДК 347.73

ББК 67.402

\section{ИМУЩЕСТВЕННОЕ НАЛОГООБЛОЖЕНИЕ КАК ОСНОВА МЕСТНОГО БЮДЖЕТА В РОССИЙСКОЙ ФЕДЕРАЦИИ ${ }^{1}$}

\author{
Петр Викторович Переверзев
}

Волгоградский государственный университет, г. Волгоград, Российская Федерация

Введение: справедливое распределение финансовых ресурсов составляет одну из основных проблем правового государства. В масштабах государства принятие решений о формировании системы доходных источников местных бюджетов и распределении средств государственного бюджета призвано обеспечить 
реализацию функций государства в условиях ограниченных доходов. В правовом регулировании этой деятельности главную роль играет взаимопроникновение норм налогового, бюджетного и муниципального права. В современной правовой науке не сложилось однозначных представлений о понятии «имущество» для целей налогообложения. Внимание исследователей заслуживают особенности современного правового регулирования этой научной проблемы. Целью настоящего научного исследования является необходимость сформулировать новые подходы в перераспределении доходов бюджетов в Российской Федерации с переносом центра тяжести основных денежных поступлений и их расходования на уровень муниципальных образований. Сегодня в отечественной правовой науке отсутствуют фундаментальные разработки, основанные на систематизации, взаимопроникновении и единстве норм различных отраслей, таких как бюджетное, налоговое и муниципальное право. Методологической основой исследования являются общенаучные методы познания, в частности, формально-юридический метод предполагает исследование правовых основ действующего бюджетного и налогового законодательства, регулирующих вопросы формирования доходных источников местных бюджетов; системный анализ объекта позволяет выделить сущностные признаки имущества как объекта местного налогообложения; сравнительно-исторический метод исследования позволяет выделить особенности правового регулирования местного налогообложения (в части формирования доходных источников и направлений расходов бюджетов) на различных этапах исторического развития; сравнительноправовой метод позволяет выявить различные подходы к налогообложению имущества в различных странах. Результаты: автором указывается определение сущностных признаков понятия «имущество» для целей налогообложения, а также выявляется комплекс проблем, возникающих в ходе применения новой нормативной базы, которая призвана обеспечить реформирование системы имущественного налогообложения в Российской Федерации. Выводы: в настоящей статье выделены этапы становления, развития, а также проблемы реформирования местного имущественного налогообложения. Предложены пути решения проблем, которые возникли в связи с проводимой реформой местного имущественного налогообложения в современной России. Область применения результатов научного исследования: настоящая научная статья имеет теоретико-прикладной характер. Выбранные научные подходы позволяют решить ряд теоретических проблем комплекса отраслей финансового и муниципального права, а также способствуют пониманию закономерностей бюджетно-правовой деятельности федеративного государства. Прикладной характер исследования может быть использован для совершенствования финансово-правового механизма обеспечения конституционно обоснованного и эффективного формирования системы доходных источников местного налогообложения.

Ключевые слова: налог на имущество, система налогов, местное налогообложение, земельный налог, кадастровая стоимость, местный бюджет.

\section{Введение}

Налогообложение имущества в настоящее время является основным источником доходов местных бюджетов в Российской Федерации. Традиционно принято считать, что имущество не случайно является объектом местного налогообложения, так как предметы материального мира (в виде недвижимости и земельных участков) труднее скрыть от налоговых органов и легче обеспечить их эффективное использование на конкретной территории. Вопрос реформирования системы имущественного налогообложения для современной России представляется чрезвычайно актуальным. Как показывает практика местного налогообложения, двух налогов явно не достаточно для формирования доходной части местных бюджетов [8, с. 15]. Процесс количественного сокращения местных налогов, нестабильность правовой базы в этой сфере налогообложения привели к возрастанию дефицита местных бюджетов в большинстве муниципальных образований [1, с. 10].

\section{О необходимости}

\section{законодательного закрепления понятия «имущество для целей налогообложения»}

На протяжении всего периода становления и развития имущественного налогообложения перед законодателем стоял вопрос об удобстве и целесообразности взимания налогов с имущества. Так, в Англии первая подать со строения была собираема по количеству дымов, но так как для взимания данного налога требовалось осматривать собственность, что связано с беспокойством граждан, такое взимание налога было упразднено и заменено 


\section{ТЕОРИЯ И ПРАКТИКА ГОСУДАРСТВЕННО-ПРАВОВОГО РАЗВИТИЯ}

обложением домов, имеющих десять окон. Окна можно посчитать, не входя в дом, следовательно взимание налога не влекло вышеуказанных неудобств [9, с. 157-158]. Во Франции наблюдается иной подход к определению того, что же будет облагаться имущественным налогом. В соответствии с законом о налоге со строений, под строением понимается любое сооружение, постоянно находящееся на одном и том же месте. При этом фундамент должен быть изготовлен из бетона или кирпича вне зависимости от материала, из которого построено само здание [4, с. 40;6, c. 90-91]. Для современного Российского налогового законодательства вопрос об определении понятия «налогооблагаемое имущество» остается ключевым. Традиционной является точка зрения о необходимости разделения предмета и объекта имущественного налога, которые, будучи обложенными, позволили при минимальных издержках налогового администрирования обеспечить максимально высокую собираемость и доходность [5, с. 2]. Однако решение этого вопроса не нашло отражения в действующем налоговом законодательстве РФ. Думается, определение понятия «налогооблагаемое имущество» должно базироваться на понятных, устойчивых характеристиках имущества как предмета материального мира, не содержащих оценочных категорий.

\section{Величина имущественных налогов}

в составе доходных источников местных бюджетов в Российской Федерации

В большей степени реформирование имущественного налогообложения было вызвано необходимостью наполнения доходных источников местных бюджетов, поэтому главной задачей, стоящей перед современной Россией, является формирование фондов денежных средств. От наполняемости этих фондов доходами зависит эффективное выполнение задач и функций государства и муниципальных образований [2, с. 37]. Министерством финансов РФ был проведен мониторинг исполнения местных бюджетов и межбюджетных отношений в субъектах РФ на региональном и муниципальном уровнях за 2016 г. [3]. По срав- нению с 2015 г. произошло снижение поступлений от местных налогов на 2,2 \% со 189,5 до 185,3 млрд рублей, а также их доли в налоговых доходах местных бюджетов с 19,0\% до $17,6 \%$.

Основной причиной является снижение на 4,5 \% (или на 7,4 млрд рублей) объема поступившего в 2016 г. в местные бюджеты земельного налога - до уровня 156,4 млрд рублей, которое частично компенсировалось увеличением на 12,5 \% поступлений от налога на имущество физических лиц (с 25,7 млрд рублей до 28,9 млрд рублей).

Удельный вес поступлений от земельного налога в налоговых доходах уменьшился с $16,4 \%$ до $14,8 \%$, а от налога на имущество физических лиц соответственно увеличился с $2,6 \%$ до $2,7 \%$.

Одним из факторов увеличения по отношению к уровню 2015 г. объема налога на имущество физических лиц является применение с 1 января 2015 г. в 29 субъектах Российской Федерации порядка определения налоговой базы по налогу на имущество физических лиц на основании кадастровой стоимости объектов налогообложения, поступления от которого зачислялись в местные бюджеты в 2016 году. С 1 января 2016 г. количество таких субъектов Российской Федерации увеличилось еще на 20 регионов. Соответственно за налоговый период 2016 г. указанный налог будет поступать в местные бюджеты в 2017 году.

\section{Заключение}

Для эффективного управления муниципальными финансами необходимо единовременно решить несколько задач: во-первых, укрепление финансовой самостоятельности органов местного самоуправления $[10$, с. 6]; во-вторых, формирование эффективного механизма бюджетного выравнивания территорий с различным финансовым потенциалом, в рамках развития и укрепления межбюджетных отношений между различными уровнями бюджетной системы Российской Федерации.

Для решения этих задач необходимо провести инвентаризацию имущества для формирования новой базы объектов имущественного налогообложения, а также определить единый порядок определения налоговой базы на 
основе рыночных показателей. При этом органы местного самоуправления не всегда должны рассматривать в качестве приоритетного направления максимально эффективное использование имущества, чтобы любыми способами обеспечить значительный рост доходов местных бюджетов от налогов на имущество, а прежде всего обязаны рассматривать местное налогообложение с позиции общей концепции организации местного самоуправления на своей территории как составную часть системы управления имуществом в Российской Федерации в целом. Для этого необходима согласованность и взаимодействие положений налогового и бюджетного законодательства Федерального центра с одной стороны, и взаимосвязь налогового и бюджетного законодательства Российской Федерации, ее субъектов и муниципальных образований с другой [7, c. 25]. На федеральном уровне необходимо законодательно закрепить определенную систему бюджетно-налоговых отношений, которая нашла бы свое дальнейшее развитие в региональном законодательстве, и их взаимоотношений с органами местного самоуправления. Для устойчивого развития местных финансов необходимо законодательно закрепить научно разработанные нормативы минимальной бюджетной обеспеченности органов местного самоуправления, создать такие финансово-правовые механизмы бюджетно-налогового взаимодействия субъектов РФ и муниципалитетов, чтобы создать и закрепить устойчивую доходную часть местных бюджетов.

\section{ПРИМЕЧАНИЕ}

${ }^{1}$ Исследование выполнено при финансовой поддержке Российского гуманитарного научного фонда в рамках научного проекта № 17-03-00308 по теме: «Налогообложение имущества как особый вид доходов местных бюджетов».

\section{СПИСОК ЛИТЕРАТУРЫ}

1. Богуславская, Н. А. Правовое регулирование местных налогов в Российской Федерации : автореф. дис. ... канд. юрид. наук / Богуславская Наталья Ароновна. - М., 2006. -22 с.

2. Васильева, Н. В. Государственные (муниципальные) доходы как финансово-правовая кате- гория // Сибирский юридический вестник. - 2015. № 1. - С. 37-42.

3. Информация о результатах проведения мониторинга исполнения местных бюджетов и межбюджетных отношений в субъектах Российской Федерации на региональном и муниципальном уровнях за 2016 год. - Электрон. текстовые дан. - Режим доступа: https://www.minfin.ru/ru/perfomance/ regions/monitoring_results/Monitoring_local/results/ \#ixzz4ockbPiSe. - Загл. с экрана.

4. Козырин, А. Н. Налоговое право зарубежных стран: вопросы теории и практики / А. Н. Козырин. - М. : Манускрипт, 1993. - 112 с.

5. Кучеров, И. И. Значение предмета и источника налогообложения для юридической конструкции налога / И. И. Кучеров // Финансовое право. 2009. - № 5. - С. $2-4$.

6. Налоговое право : учеб. пособие / под ред. С. Г. Пепеляева. - М. : ИД ФБК-ПРЕСС, 2000. -608 c.

7. Переверзева, Е. В. О некоторых проблемах функционирования бюджетно-налогового механизма в современной России / Е. В. Переверзева, П. В. Переверзев, А. А. Полянская // Тенденции и инновации современной науки : материалы XIX Междунар. науч.-практ. конф. (тезисы докладов). 29 марта 2017 г. : сб. науч. тр. - Краснодар, 2017. - 44 с.

8. Савостьянова, С. А. Правовое регулирование доходов местных бюджетов / С. А. Савостьянова // Финансовое право. - 2011. - № 9. - С. 14-18.

9. Сперанский, М. М. У истоков финансового права / М. М. Сперанский, Н. И. Тургенев, М. Ф. Орлов. - М. : Статут, 1998. - 432 с. - (Серия «Золотые страницы финансового права»).

10. Тория, Р. А. Повышение эффективности межбюджетных отношений и качества управления государственными и муниципальными финансами в Российской Федерации / Р. А. Тория // Финансовое право. - 2012. - № 3. - С. 6-11.

\section{REFERENCES}

1. Boguslavskaya N.A. Pravovoe regulirovanie mestnykh nalogov v Rossiyskoy Federatsii: avtoref. dis. ... kand. yurid. nauk [Legal Regulation of the Local Taxes in the Russian Federation. Cand. jurid. sci. abs. diss.]. Moscow, 2006. 22 p.

2. Vasilyeva N.V. Gosudarstvennye (munitsipalnye) dokhody kak finansovo-pravovaya kategoriya [State (Municipal) Revenues as a Financial and Legal Category]. Sibirskiy yuridicheskiy vestnik, 2015, no. 1, pp. 37-42.

3. Informatsiya o rezultatakh provedeniya monitoringa ispolneniya mestnykh byudzhetov $i$ mezhbyudzhetnykh otnosheniy $v$ subyektakh Rossiyskoy Federatsii na regionalnom $i$ munitsipalnom urovnyakh za 2016 god [Information 


\section{ТЕОРИЯ И ПРАКТИКА ГОСУДАРСТВЕННО-ПРАВОВОГО РАЗВИТИЯ}

on Results of Carrying Out Monitoring of Execution of Local Budgets and Interbudgetary Relations in the Subjects of the Russian Federation at the Regional and Municipal Levels for 2016]. URL: https://www. minfin.ru/ru/perfomance/regions/monitoring_results/ Monitoring_local/results/\#ixzz4ockbPiSe.

4. Kozyrin A.N. Nalogovoe pravo zarubezhnykh stran: voprosy teorii i praktiki [Tax Law of Foreign Countries: Issues of Theory and Practice]. Moscow, Manuskript Publ., 1993. 112 p.

5. Kucherov I.I. Znachenie predmeta i istochnika nalogooblozheniya dlya yuridicheskoy konstruktsii naloga [Value of a Subject and Source of Taxation for Tax Legal Design]. Finansovoe pravo, 2009, no. 5, pp. 2-4.

6. Pepelyaev S.G., ed. Nalogovoe pravo: uchebnoe posobie [Tax Law: Study Guide]. Moscow, ID FBK-PRESS, 2000. 608 p.

7. Pereverzeva E.V., Pereverzev P.V., PolyanskayaA.A. O nekotorykh problemakh funktsionirovaniya byudzhetno-nalogovogo mekhanizma v sovremennoy Rossii [About Some Problems of Functioning of the Budgetary and Tax Mechanism in Modern Russia].
Tendentsii i innovatsii sovremennoy nauki: materialy XIX Mezhdunar. nauch.-prakt. konf. (tezisy dokladov). 29 marta 2017 g.: sb. nauch. tr. [Tendencies and Innovations of Modern Science: Proceedings of the $19^{\text {th }}$ International Scientific and Practical Conference (Theses of Reports), March 29, 2017. Collection of Scientific Works]. Krasnodar, 2017. 44 p.

8. Savostyanova S.A. Pravovoe regulirovanie dokhodov mestnykh byudzhetov [Legal Regulation of Income of Local Budgets]. Finansovoe pravo, 2011, no. 9, pp. 14-18.

9. Speranskiy M.M., Turgenev N.I., Orlov M.F. U istokov finansovogo prava. Moscow, Statut Publ., 1998. 432 p. [At the Origins of Financial Law].

10. Toriya R.A. Povyshenie effektivnosti mezhbyudzhetnykh otnosheniy i kachestva upravleniya gosudarstvennymi i munitsipalnymi finansami $\mathrm{v}$ Rossiyskoy Federatsii [Increase in Efficiency of the Interbudgetary Relations and Quality of Management of the Public and Municipal Finances in the Russian Federation]. Finansovoe pravo, 2012, no. 3, pp. 6-11.

\section{Information about the Author}

Peter V. Pereverzev, Postgraduate Student, Department of Constitutional and Municipal Law, Volgograd State University, Prosp. Universitetsky, 100, 400062 Volgograd, Russian Federation, pereverzevpv@mail.ru,kmp@volsu.ru.

\section{Информация об авторе}

Петр Викторович Переверзев, аспирант кафедры конституционного и муниципального права, Волгоградский государственный университет, просп. Университетский, 100, 400062 г. Волгоград, Российская Федерация, pereverzevpv@mail.ru, kmp@volsu.ru. 